\title{
DigitAL AND OFFLINE
}

Partial Fields and Knowledge Producers

\section{Narmala Halstead}

\begin{abstract}
Partial processes of knowledge making, online and offline, demonstrate modes of experiential newness. Indicative of the 'shocks' and joined curations of field encounters, such experiences re-engage anthropological debates as being of the present. The extended field suggests vast change and unlimited spaces to engage participants and 'invite' new unrelatable publics. The reflections and encounters disturb an apparent mandate of digital anthropology as a sub-discipline to 'upturn' field and knowledge approaches. As these forum articles indicate, this vision of the field is not easily dissociated from continuities with participants as knowledge producers in and out of offline interactions. Notions of exit and entry or participants gaining seemingly unlimited new access to fieldworkers remain connected to performative/curated forms of field relations, while attuned to an ongoing ethnographic present.
\end{abstract}

Keywords: co-location, digital anthropology, field encounters, interlocutors, performativity, positionality, researcher-activist

Reflecting on an extended field online and offline, this forum offers timely reminders about certain vested capacities of digital anthropology, tasked with vastly transforming anthropological field engagements and offering spaces for retheorizing the discipline itself. Such conceived breadth of digital anthropology, ${ }^{1}$ which appears understandable in terms of both envisaged access for multiple publics and concomitant views of transparency, can eclipse long-standing anthropological self-scrutiny.

While critically examining digital anthropology's 'claims' to such mandates, the forum demonstrates that familiar field relations and encounters often persist under newly emphasized conditions. The claims and expectations surrounding digital anthropology afford spaces to interrogate or make 'sideways' 
sense of the construct of newness alongside the existing scholarship on fieldwork encounters and related issues.

The forum, generally, extends questioning of access and boundary making amid ideas of the field and knowledge producers. This further disturbs a sense of wholeness attached to what digital anthropology can or might deliver in terms of specific field interactions and claims for its contributions to the discipline. Engaging and disengaging with particular boundaries vis-à-vis such a digital whole remains very much about the partiality of knowledge constructions and approaches. This afterword elaborates on specific issues to complement certain points about access relations and knowledge co-production.

An early example involves the diary of Bronislaw Malinowski ([1969] 1989). Written between 1914-1915 and never meant to be published, its posthumous release was to 'trouble' the field relationships that could not be 'brought to belong' to research data accounts. Much later, anthropologists would benefit from postmodernist interventions, all the more significant following Writing Culture, to reconsider unacknowledged issues of co-authorship and to challenge 'static' theorizing in 'us' and 'them' divides. Thus, anthropologists have consistently revisited critiques such as the romanticized idea of a bounded field site occupied by a lone fieldworker and the construct of the traditional geopolitical West seeking knowledge of others who can only be known through the prescribed research endeavors (see, e.g., Halstead et al. 2008; Olwig and Hastrup 1997). Further, theoretical frames have to remain attentive to other implied exclusions and new forms of othering while considering transformative capacities of digital anthropology in contributing to the discipline as a whole (Miller 2012, 2021).

The ways it is possible to revisit or re-experience anew issues that have long been discussed-given the extensive scholarship—relate to the varied examples in this forum. I recollect my own entry into the field and subsequent immersion where certain interlocutors examined my presence by questioning anthropology's role as overtly aligned with the colonial project of othering (Halstead 2006). This vestige of anthropology's colonially implicated past had never left this present (with the discipline's own self-lacerations absent in the lay discourses, here). From these interlocutors' positions, coming under anthropological focus was strange, and thus to be othered in turn. These interactions directed my attention to dynamics of research participants' partial and contextual appearances. In the ensuing years of long-term research, the many field encounters added to the capacities for fresh realizations and continuities.

A notion of the present-diversely experienced (and constituted)-returns to how immersion in the field relates to a co-presencing that attempts to speak for and with the other, and can provoke constant re-engagement with disciplinary concerns. This illuminates the spaces for experiential newness, arising at times through shocks of managing field relations from vantage points that 
seek or expect same-side positionality or at the least encompassment with the other. This preamble now turns to the challenges and changing forms of immersion in 'staying connected' in these more visible field sites-on and off the digital-which can provide for innovative interplays. Further, certain fieldwork concerns endure, and within a particular present they provide spaces to differentially illuminate or extend commonly understood field relations.

\section{Expertise and Different Publics}

The themes in this forum bear on both the problematic and productive forms of engagement that have variedly marked field encounters. Such thematic issues relate invariably to how the field is constituted and to ideas of exit and entry amid the reflexive scrutiny of encounters. Differing categories of knowledge producer-as assemblages materializing not just for those being studied, but also for the researcher, in partial and interconnected fields-turn to the view of the anthropologist as 'located' on the basis of expertise in the specified areas (Strathern 1987). Thus, ideas of native knowledge reverberate in terms of the dynamics of expertise alongside ownership of homelands/identities. Extended publics, more visibly so, include those who want to be 'native' (as experts), which is indicative of the crowded juxtapositions on digital sites.

At the least, questions arise about what boundaries can be (re)imposed in a field co-occupied and reimagined by research participants and unknown others, the latter as unrelatable publics. While questioning the anthropologist's presence has always been a fieldwork staple (see, e.g., Brettell 1993; Halstead 2006), an increased potential for misapprehension of the researcher's work, presence, and identity arises.

Thus, Rosa Cordillera A. Castillo, as a researcher of her own country, notes concerns that include safety issues for family members at home. An online commentary interrogating categories of victim and perpetrator went viral, demonstrating her activist profile. Faced with the 'violence' of different populist writers being inattentive to the shared nature of victimhood, Castillo became ultra-visible in this activist role to intervene in these representations. She had to balance her halfie positionality and her visibility on Facebook in this lived interconnectivity of belonging and extended research activities. However, while it exposed her to threats from particular kinds of publics, it also brought out further support and new ties through social media connectivity.

Geoffrey Hughes was at home when a particular lack of field exit ensued: multiply occupied stranger-publics directed unfounded claims of spying against him. On these post-fieldwork 'non-relations', he notes that becoming the focus of "hundreds of complete strangers debating his identity struck him as far more unnerving than a direct accusation from an individual." Events quickly 
escalated online before the situation petered out. While variously discussed in the literature, issues of spying or being misunderstood in terms of certain positionalities occur alongside the ways that the field can be specifically bounded, such as through research agendas or research participants' own forms of distancing and curating. The notion of exit, here, shifts to bring out activism in 'engaging' with other publics.

These security risks and privacy concerns differ from the fieldwork diligence and online and offline curating of relations in the accounts of Liana Chua and of Nanneke Winters. Also, despite having been active in dangerous field sites, Jason Scott relates how he dealt with interlocutors conscious of their own failures rather than those who chose to target the researcher.

\section{Exit and 'Being There'}

Felix Girke points to the problem of needing to curtail or redefine the field through different kinds of exit. However, he notes that it is "no longer feasible to cleanly sever those ties established 'there' as it had been for our predecessors." This points to the new technological access of participants, which somewhat sidesteps traditional ways of not severing ties. Girke does discuss the much-delayed exit, raising the example of the return visits of his mentor, who will never really leave. Girke also considers that some anthropologists facing particular constraints-personal or research trajectories-have no choice but to leave. Separately, Anna-Maria Walter examines how ongoing spaces of communication as a form of 'return' have the impact of creating other forms of distanciation, so that in these latest modes of communication her status as an adopted family member and 'milk sister' is to be re-experienced as a kind of dissolution and absence. Any concerns about leaving were yet to take form for Chiara Cocco and Aleida Bertran as their field abruptly restarted online during COVID-19 for both researchers and participants. The difficulties they encountered added to the truism that people do not live online alone. They entered the field at a point of 'pioneering' change as defined by the pandemic and expected its closure (exit) at the end of the festival.

Ideas of long-term immersion as a fieldwork staple, definitive of 'being there', are more readily being disturbed by recent retheorizing of short or infrequent returns. Views of physical stays as limiting can overshadow the embedded partiality of anthropological knowledge endeavors as also being without other kinds of closures. Marilyn Strathern's (1999) 'ethnographic moment'the co-inhabiting of ethnography's double fields-allows for realizations at different moments in and out of the physical field site. Such understandings come into more contemporary focus under the umbrella term of 'patchwork ethnography' to refer not “to one-time, short, instrumental trips and relationships à la 
consultants, but rather, to research efforts that maintain the long-term commitments, language proficiency, contextual knowledge, and slow thinking" (Günel et al. 2020). Here, Chua turns to further reflect on this multiply composed ethnographer as one who moves constantly "in and out of view, while sustaining multiple fictions and relations."

In Winter's exploration of very fraught dangerous migrant crossings as extended connectivity, a need for the discipline being constituted through the specter of the lone researcher in a single locality (sans critiques) appears important to bring out the methodological contributions being garnered under "trajectory research." Noting the literature, Winters reflects that our methods should "also be on the move or at least attuned to mobility." These concerns encircle a methodologically broad extension of the field that incorporates a host of innovations, such as the use of video diaries, and also shows how migrants follow researchers online and communicate with them. These issues are suggestive of spaces to further mine a 'return trajectory' in illuminating knowledge practices that incorporate cutting into the broad sites, while not limiting the field.

\section{Relations and Performativity}

An idea of distinct, if moment to moment, bounded settings of researcher and researched returns to the performative processes of these relations amid their fluidity. The messing (unraveling and/or remaking) of boundaries vis-à-vis entering and exiting can destabilize the notion of participants as 'awaiting' peoples. This challenges a positioning within a formalistic process of research objectification (Chua, Girke, Scott). As an embedded anthropological approach, these accounts extend what has always transpired in the 'pre-digital' field. Anthropologists have long reflected on the 'rituals' where they come to belong with the 'others'. Online and offline curations unveil the performative capacities in field encounters, including efforts to change researchers into familiars. Going beyond another kind of fiction, these interactions add to participants' self-curating forms, even as they examine the anthropologist, extending 'self and other' interlocutory exchanges.

Chua writes about upgrading her boyfriend to the status of fiancé upon entering the field. This was a persuasive effort at co-presencing accepted by her interlocutors. Chua notes how difficult it would be to maintain this fiction presently, given Facebook friendships with participants. In Chua's extended digital field, the arrival of her participants is accompanied by their new forms of curating, elevated through greater access and at levels of sharedness into the researcher's worlds (see also Castillo). Thus, a certain separation between researcher and participant-host that collapses becomes re-performed in relation 
to 'acceptance rituals'. This acknowledges that participants' acceptance of the self-representations of researchers can rely on or be marked by participants' own expressed or tacit truths (see Halstead et al. 2008).

\section{Presence, Absence, and Co-location}

In Winters's accounts, performative spaces emerge in the contrasting appearances of a key participant whose communication of despair and hopelessness was to be retracted the very next day into a positive testimony. This participant was to be known through the later and explicitly curated presentation rather than through her earlier unguarded, vulnerable outpouring. Winters noted that this participant's WhatsApp profile photograph threw her off balance, as it depicted "a radiant, confident, and well-groomed young lady." Thus, this curated image was to dislodge any likely understandings of anxiety and despair that might also prevail, more generally, in these journeys. Such social media spaces emerge as particular kinds of continuity forms (if intensely so), to extend how participants have managed their self-representations and other field relations. This allows for differences that can build on rather that function to replace face-to-face field encounters in the new online co-locations.

Other concerns emerge to re-engage the distinction where researchers seek or note the explicit absence of sentiment online. For Cocco and Bertran, the unexpected change of the field due to the pandemic led to a focus on sentiment through proffered distinctions of physical presences and immersion (at the different online levels). The field site was all the more to be developed through the notion of a festival performance while having its own limits to performative roles of fictions and truths in entering the field. Studying the explicit performance of an online festival, they find hope in the being of 'being there'.

However, in reflecting on the limitations of extensive social media activism, Scott considers an absence where it is difficult to trace sentiment online. Scott's differing reactions to the deaths of two children, occurring four years apart, brought out a distinction between offline and online immersion where, in contrast to the first, his reaction to the second death was "emotionally cooler.” Doubtful of digital anthropology's capacity for unlimited access, Scott returns to consider his own traditional long-term immersive fieldwork, which, in itself, becomes more definitive as the accessible field. The seeming infinite reach of social media becomes curtailed. Here, social media becomes spaces to reaffirm rather than to radicalize and, thus, to limit hope in struggles for justice. It relates to embedded limits of online capacities despite the widening digital reach, which is often acclaimed over and above traditional media. This example also turns on its head the notion of a wholeness of capacities within the digital. 


\section{Concluding Notes}

This forum offers opportunities to reflect on the ways that digital anthropology is more interconnected to traditional concerns and notions of continuity than ideas of its whole capacities and newness might suggest. Other related anthropological debates also arise. The signaling of capacities turns attention to both the 'project' of the ethnographer's self-reflection and scrutiny and new levels of access by participants to the researcher's world.

In some instances, participants newly display themselves as kinds of knowledge producers, if performatively so, as particular materializations of anthropologists and interlocutors co-inhabiting the field. Ideas of co-location, extended online, are rendered in presences and absences: different knowledge endeavors and information sharing become bits and pieces to be proffered as contextually bounded. Further, new responsibilities emerge alongside researcher-activist roles and the inherent knowledge capacities within anthropology to generally engage wider publics. The reflections indicate a broader scale as well as certain definitive understandings of the digital as a revelatory agent to build on ideas of limitations (lesser publicness) of engaged field encounters and to impose new limits. Offline and online interactions remain open to scrutiny as incomplete in the continual process of assessing knowledge claims and representations.

Narmala Halstead is a Research Associate at the University of Sussex and has held faculty positions at Cardiff University and the University of East London. She is carrying out research on social media/digital technologies, socio-legal and political narratives, and new forms of migration. Publications include her recent monograph Competing Power: Landscapes of Migration, Violence and the State (2018). She is the editor of the Journal of Legal Anthropology. E-mail: narmala.halstead@sussex.ac.uk

\section{Note}

1. Ideas of a struggling status for sub-disciplines-for instance, in terms of an earlier marginal status of a 'parent' media anthropology_are seen to shift in the 'visibilities' of what digital anthropology can offer. On this basis, digital anthropology as a sub-discipline 'pushes' past any marginality issues in terms of its relation to 'anthropology proper'. 


\section{References}

Brettell, Caroline. 1993. When They Read What We Write: The Politics of Ethnography. Westport, CT: Bergin \& Garvey.

Günel, Gökçe, Saiba Varma, and Chika Watanabe. 2020. “A Manifesto for Patchwork Ethnography.” Member Voices, Fieldsights, 9 June. https://culanth.org/ fieldsights/a-manifesto-for-patchwork-ethnography.

Halstead, Narmala. 2006. "Others In and Of the Field: Anthropology and Knowledgeable Persons.” In Critical Journeys: The Making of Anthropologists, ed. Gert De Neve and Maya Unnithan-Kumar, 47-66. Aldershot: Ashgate.

Halstead, Narmala, Eric Hirsch, and Judith Okely, eds. 2008. Knowing How to Know: Fieldwork and the Ethnographic Present. New York: Berghahn Books.

Malinowski, Bronislaw. (1967) 1989. A Diary in the Strict Sense of the Term. 2nd ed. London: Athlone Press.

Miller, Daniel. 2012. “Open Access, Scholarship, and Digital Anthropology.” HAU: Journal of Ethnographic Theory 2 (1): 385-411.

Miller, Daniel. 2021. "A Theory of a Theory of the Smartphone.” International Journal of Cultural Studies, 24 February. https://doi.org/10.1177/1367877921994574.

Olwig, Karen Fog, and Kirsten Hastrup, eds. 1997. Siting Culture: The Shifting Anthropological Object. New York: Routledge.

Strathern, Marilyn. 1987. "The Limits of Auto-Ethnography.” In Anthropology at Home, ed. Anthony Jackson, 16-37. London: Tavistock.

Strathern, Marilyn. 1999. Property, Substance and Effect: Anthropological Essays on Persons and Things. London: Athlone Press. 